\title{
Cerebral embolism caused by a left cardiac ventricle metastatic tumor
}

Figure Results of MRI, transthoracic echocardiography, CT, and histology
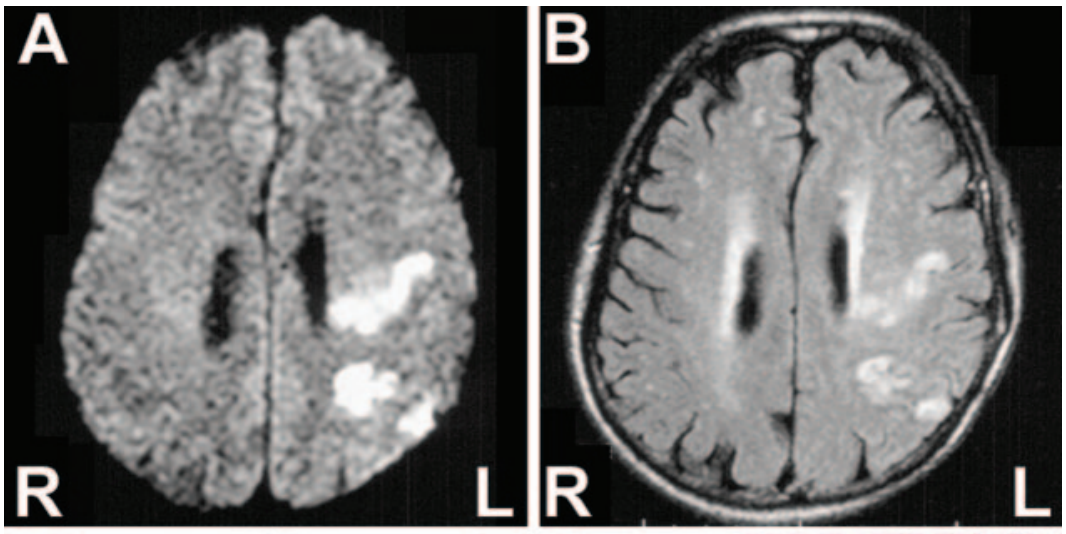

Diffusion-weighted (A) and fluid-attenuated inversion
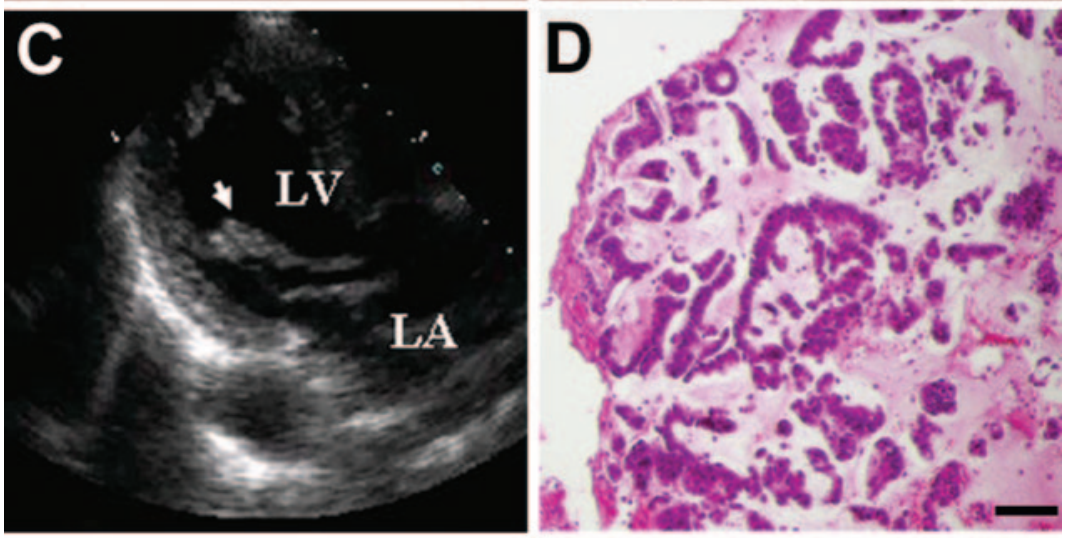
recovery (B) imaging show multiple brain infarctions. Transthoracic echocardiography (C) shows an abnormal mass (arrow), and histology (D) reveals mucinous adenocarcinoma. Initial CT (E) shows a faint lowdensity area. Follow-up CT (F) reveals a metastatic tumor with edema. $L V=$ left ventricle; $L A=$ left atrium. Scale $=100 \mu \mathrm{m}$.
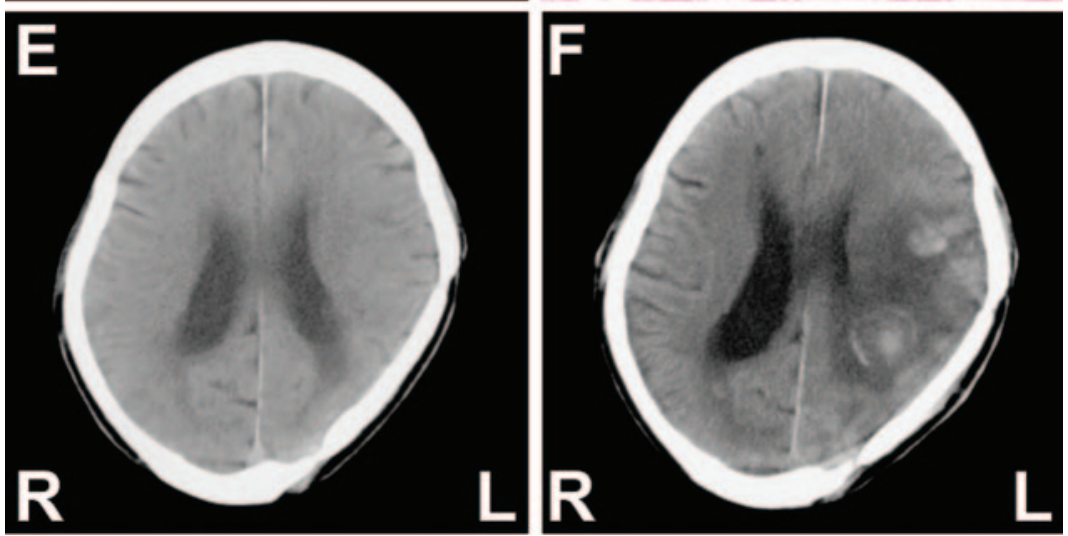

A 71-year-old man with metastatic lung cancer was admitted to our hospital, complaining of sudden onset of severe weakness of his arm and speech disturbance. He had been treated with 5 -fluorouracil and was completely independent in his daily life. MRI revealed multiple infarctions within the left hemisphere (figure). Transthoracic echocardiography showed a mobile mass. Three months later, follow-up CT revealed multiple metastases at the infarct region. 
Cerebral infarction is a common complication associated with cancer. ${ }^{1,2}$ However, there are few reports that follow the events of cerebral embolism by a left ventricle metastatic tumor and subsequent brain metastasis with diagnostic images.

Y. Yagita, MD, PhD, K. Kitagawa, MD, PhD, K. Matsushita, MD, PhD, S. Furukado, MD, K. Kajimoto, MD, PhD, M. Sakaguchi, MD, PhD, M. Hori, MD, PhD, and S. Sakoda, MD, PhD, Osaka, Japan

Disclosure: The authors report no conflicts of interest.

Address correspondence and reprint requests to Dr. Y. Yagita, Stroke Division, Department of Neurology, Osaka University Graduate School of Medicine, 2-2, Yamadaoka, Suita, Osaka 565-0871, Japan; yagita@medone.med.osaka-u.ac.jp

\section{REFERENCES}

1. Graus F, Rogers LR, Posner JB. Cerebrovascular complications in patients with cancer. Medicine (Baltimore) 1985;64: $16-35$.

2. Amico L, Caplan LR, Thomas C. Cerebrovascular complications of mucinous cancers. Neurology 1989;39:522-526. 


\section{Neurology}

\section{Cerebral embolism caused by a left cardiac ventricle metastatic tumor}

Y. Yagita, K. Kitagawa, K. Matsushita, et al.

Neurology 2007;69;407-408

DOI 10.1212/01.wnl.0000269793.24393.f9

This information is current as of July 23, 2007

\section{Updated Information \&} Services

References

Permissions \& Licensing

Reprints including high resolution figures, can be found at: http://n.neurology.org/content/69/4/407.full

This article cites 2 articles, 1 of which you can access for free at: http://n.neurology.org/content/69/4/407.full\#ref-list-1

Information about reproducing this article in parts (figures,tables) or in its entirety can be found online at:

http://www.neurology.org/about/about_the_journal\#permissions

Information about ordering reprints can be found online: http://n.neurology.org/subscribers/advertise

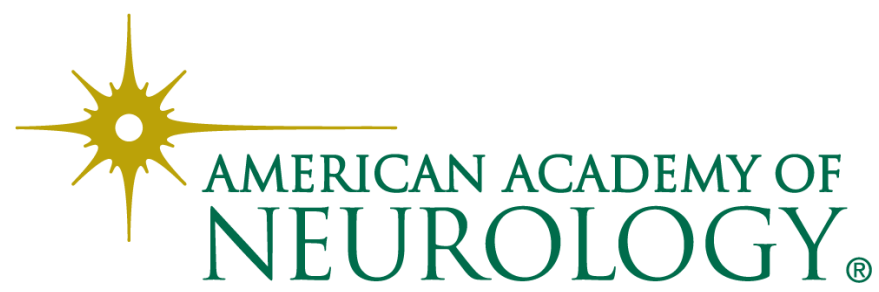

